\title{
Selective visual processing with tilt and color cues
}

\author{
GORDON D. LOGAN \\ University of Waterloo, Waterloo, Ontario, Canada N2L $3 G 1$
}

\begin{abstract}
Subjects searched two-, four-, six-, and eight-letter arrays for the presence of a $\mathrm{T}$ or $\mathrm{L}$. The position of the target was cued by coloring it red or tilting it $45 \mathrm{deg}$ (Experiment 1), and by tilting it 15 or $30 \mathrm{deg}$ (Experiments 2 and 3 ). In general, reaction times to cued targets were faster than no-cue controls, and the savings increased with array size. A smaller amount of savings was observed when cue and no-cue trials varied randomly (Experiment 3) than when they were blocked (Experiments 1 and 2).
\end{abstract}

There is widespread belief in our ability to selectively process portions of a cluttered visual array without the aid of eye movements (e.g., Neisser, 1967). An important feature of this belief is the notion that selective processing is efficient, that is, the use of a cue indicating the target's position leads to better performance than processing without the cue. The primary evidence supporting this view is the proportional improvement in accuracy when reporting a subset of an array over attempting to report the entire array. This is known in the literature as partial-report superiority, and is easily replicable (see Dick, 1974, for a review). The subset reported is either a single item indicated by a bar marker (Averbach \& Coriell, 1961) or several items sharing a common value on some dimension other than item identity which is cued by a tone (Sperling, 1960).

However, partial-report superiority entails a serious confound which challenges the perceptual efficiency interpretation: The response set in partial report is always smaller than that when the whole array must be reported (whole report). Proportional improvement in accuracy may reflect a smaller load on memory or fewer opportunities for output interference rather than more efficient perceptual processing (Dick, 1971). Thus, the efficiency of selective processing is not as well documented as it might appear.

The detection paradigm provides a promising alternative. Here, subjects indicate which of two prespecified targets is present in an array, and the response set is the same whether or not the target's position is cued. Thus, the finding of faster reaction times to targets cued by a bar marker than to control targets without a cue (Holmgren, 1974; Logan, Note 1; Logan \& Withey, Note 2) indicates more efficient perceptual processing rather than memory load or output interference factors.

The present experiments were designed to extend

This research was supported by two grants from the National Research Council of Canada: A95 to M. P. Bryden and APA231 to P.M. Merikle. M. P. Bryden sponsors this paper and takes full editorial responsibility for its content. Requests for reprints should be sent to Gordon D. Logan, Department of Psychology, Erindale College, University of Toronto, Mississauga, Ontario, Canada. these findings to cues that are dimensions of the letters themselves, apart from letter identity. In Experiment 1 the target was red or tilted $45 \mathrm{deg}$ to the right (cued conditions), or black and in normal orientation like the nontarget letters (no-cue condition). Experiments 2 and 3 compared 15- and 30-deg tilts as cues. In Experiments 1 and 2 each cue and control condition was run in a separate block, while in Experiment 3 cue and control conditions varied randomly from trial to trial.

\section{METHOD}

\section{Subjects}

Each experiment employed a separate group of 12 University of Waterloo students who were paid for serving in one 1-h session.

\section{Apparatus and Stimuli}

The arrays were presented in a Scientific Prototype tachistoscope (Model GB) at a luminance of $14 \mathrm{fL}$. A fixation field of the same luminance preceded and followed each array. Reaction time was measured in milliseconds from the onset of the array.

The arrays contained two, four, six, or eight different capital letters (Letraset 287) equally spaced on the circumference of an imaginary 2-deg circle centered on the fixation point. Each array size was represented by 24 different arrays in which each target letter appeared in each position equally often. With eightletter arrays, $T$ appeared once and $L$ twice in odd-numbered positions, and $\mathrm{T}$ twice and $\mathrm{L}$ once in even-numbered positions. The same set of 24 arrays was used for each array size in each cuing condition, so that the set of noise items was identical across cuing conditions. Altogether, 288 arrays were used.

In Experiment 1 the arrays were exposed for $500 \mathrm{msec}$, while in Experiments 2 and 3 the exposure duration was $200 \mathrm{msec}$. In all experiments the click of the switch initiating the tachistoscope timers occurred $500 \mathrm{msec}$ before the onset of the array to serve as a warning signal. In addition, subjects replied to a verbal ready signal before the timers were activated.

\section{Procedure}

Subjects were required to indicate whether each array contained a $\mathrm{T}$ or an $\mathrm{L}$ by pressing one of two buttons on a panel in front of them. Half of the subjects pressed the left button for $T$ and the right for $L$, and the remaining subjects did the opposite. When the three cuing conditions were blocked (Experiments 1 and 2), all six possible orders of the conditions were used. Two subjects received each order, one with each assignment of target letters to response buttons. In Experiment 3, where cuing conditions were random, similar orders were employed. In all experiments, array size varied randomly within blocks, with the constraints that each array size occurred equally 
often and that each target letter occurred equally often with each array size.

Instructions stressed both speed and accuracy. Each experiment was preceded by 72 practice trials using single letters, 24 of each cue type. Cue type varied randomly from trial to trial. Feedback regarding speed and accuracy was given during practice but not during the experiments themselves.

\section{RESULTS AND DISCUSSION}

In each experiment, each subject completed 24 trials in each cuing condition with each array size. Mean correct reaction times were computed for each subject for each combination of cuing condition and array size. Means and error rates across subjects appear in Table 1. Summary statistics from two-way analyses of variance (array size by cuing condition) performed on the reaction time data from each experiment are presented in Table 2.

Two features are prominent in the data from all three experiments: First, the presence of a cue reduced reaction time relative to no-cue controls, and the savings increased with array size. At least in Experiments 2 and 3 , where the arrays were exposed for $200 \mathrm{msec}$, there is evidence that efficient selective processing can occur without eye movements. The present data thus extend previous findings with bar-marker cues to cues that are properties of the letters themselves.

In Experiments 1 and 2, the amount of savings was not affected by the type of cue. In Experiment 1, red

Table 1

Mean Reaction Times in Milliseconds and Proportions of Errors in All Conditions of the Three Experiments

\begin{tabular}{|c|c|c|c|c|c|}
\hline \multirow[b]{2}{*}{ Condition } & \multirow[b]{2}{*}{ Measure } & \multicolumn{4}{|c|}{ Array Size } \\
\hline & & 2 & 4 & 6 & 8 \\
\hline & & \multicolumn{4}{|c|}{ Experiment 1} \\
\hline Control & $\begin{array}{l}\text { RT } \\
\text { Error }\end{array}$ & $\begin{array}{r}479 \\
.05\end{array}$ & $\begin{array}{r}524 \\
.05\end{array}$ & $\begin{array}{r}553 \\
.05\end{array}$ & $\begin{array}{r}624 \\
.07\end{array}$ \\
\hline Red & $\begin{array}{l}\text { RT } \\
\text { Error }\end{array}$ & $\begin{array}{r}467 \\
.05\end{array}$ & $\begin{array}{r}496 \\
.05\end{array}$ & $\begin{array}{r}523 \\
.03\end{array}$ & $\begin{array}{r}551 \\
.10\end{array}$ \\
\hline \multirow[t]{2}{*}{$45 \mathrm{deg}$} & $\begin{array}{l}\text { RT } \\
\text { Error }\end{array}$ & $\begin{array}{r}467 \\
.03\end{array}$ & $\begin{array}{r}489 \\
.06\end{array}$ & $\begin{array}{r}511 \\
.03\end{array}$ & $\begin{array}{r}535 \\
.04\end{array}$ \\
\hline & & \multicolumn{4}{|c|}{ Experiment 2} \\
\hline Control & $\begin{array}{l}\text { RT } \\
\text { Error }\end{array}$ & $\begin{array}{r}512 \\
.03\end{array}$ & $\begin{array}{r}556 \\
.03\end{array}$ & $\begin{array}{r}618 \\
.05\end{array}$ & $\begin{array}{r}651 \\
.05\end{array}$ \\
\hline $15 \mathrm{deg}$ & $\begin{array}{l}\text { RT } \\
\text { Error }\end{array}$ & $\begin{array}{r}498 \\
.05\end{array}$ & $\begin{array}{r}516 \\
.03\end{array}$ & $\begin{array}{r}561 \\
.03\end{array}$ & $\begin{array}{r}599 \\
.07\end{array}$ \\
\hline $30 \mathrm{deg}$ & $\begin{array}{l}\text { RT } \\
\text { Error }\end{array}$ & $\begin{array}{r}496 \\
.06\end{array}$ & $\begin{array}{r}521 \\
.03\end{array}$ & $\begin{array}{r}555 \\
.03\end{array}$ & $\begin{array}{r}593 \\
.05\end{array}$ \\
\hline & & \multicolumn{4}{|c|}{ Experiment 3} \\
\hline Control & $\begin{array}{l}\text { RT } \\
\text { Error }\end{array}$ & $\begin{array}{r}506 \\
.02\end{array}$ & $\begin{array}{r}546 \\
.03\end{array}$ & $\begin{array}{r}602 \\
.04\end{array}$ & $\begin{array}{r}653 \\
.06\end{array}$ \\
\hline $15 \mathrm{deg}$ & $\begin{array}{l}\text { RT } \\
\text { Error }\end{array}$ & $\begin{array}{r}516 \\
.03\end{array}$ & $\begin{array}{r}549 \\
.03\end{array}$ & $\begin{array}{r}594 \\
.02\end{array}$ & $\begin{array}{r}601 \\
.07\end{array}$ \\
\hline $30 \mathrm{deg}$ & $\begin{array}{l}\text { RT } \\
\text { Error }\end{array}$ & $\begin{array}{r}503 \\
.03\end{array}$ & $\begin{array}{r}539 \\
.04\end{array}$ & $\begin{array}{r}564 \\
.04\end{array}$ & $\begin{array}{r}609 \\
.06\end{array}$ \\
\hline
\end{tabular}

Table 2

Summary Statistics from Two-Way ANOVAs on Mean Reaction Times

\begin{tabular}{|c|c|c|c|c|}
\hline \multirow[b]{2}{*}{ Effect } & \multirow[b]{2}{*}{ df } & \multicolumn{3}{|c|}{ F Ratios } \\
\hline & & \multicolumn{3}{|c|}{ Experiment } \\
\hline Array Size (A) & $3 / 33$ & $85.94 * *$ & $78.34 * *$ & $86.10^{* *}$ \\
\hline Cuing Conditions (C) & $2 / 22$ & $13.11 * *$ & $7.01 * *$ & $4.86^{*}$ \\
\hline A by $C$ & $6 / 66$ & $5.59 * *$ & $3.24 * *$ & $4.96 * *$ \\
\hline${ }^{*} p$ & & & $* p<.01$ & \\
\hline
\end{tabular}

letters were as effective as cues as were letters tilted $45 \mathrm{deg}$. This may only reflect a fortuitous selection of equivalent points on the separate psychophysical functions for the two cue types, but the equivalence of 15- and 30-deg tilts in Experiment 2 is more impressive. In Experiment 3, much less savings was found, and 15-deg cues appeared less efficient than 30-deg cues. Specifically, 15-deg tilt produced reliable savings only with eight-letter arrays, while 30-deg tilt produced substantial savings with six- and eight-letter arrays. By contrast, all cue types in Experiments 1 and 2 produced reliable savings with four-, six-, and eightletter arrays.

These differences suggest an expectancy effect: When cuing conditions were blocked (Experiments 1 and 2), subjects could prepare specifically for each type of cue, including the no-cue condition, and such preparation may have compensated for idiosyncratic processing requirements of the different cue types. When cuing conditions varied randomly from trial to trial (Experiment 3), subjects could either prepare specifically for the cue type they anticipate on the next trial or time-share preparation for each cue type. Either strategy would produce less efficient performance with a cue, both in general and for specific cue types. Perhaps 15-deg cues were only slightly more difficult than 30-deg cues so that performance differences would only emerge under time-sharing conditions.

The expectancy effects appear to be restricted to the 15- and 30-deg tilt conditions; no-cue performance was remarkably similar in Experiments 2 and 3. Preparation for no-cue arrays would seem to have been as effective when cuing conditions varied randomly as when they were blocked. Possibly, subjects adopted a "protective" strategy, selectively preparing for the no-cue condition at the expense of the other cuing conditions. Thus, performance with no-cue arrays would be optimal, while performance with 15- and 30-deg cues would suffer. Alternatively, no-cue processing may be an automatic default operation, so that only preparation for the 15 and 30-deg cues need be time shared. In either case, expectancy effects would be restricted to conditions involving a cue.

The second general feature of the data is that the use of a cue did not eliminate the array-size effect. Reaction 
time increased with array size for every type of cue. There exist at least four interpretations of this effect.

The first interpretation is lateral masking. The increase in reaction time with array size may result from stronger inhibitory interaction between adjacent letters as the space between them is reduced (Estes, 1972). However, since the spatial limit of lateral masking is less than $1 \mathrm{deg}$ (Collins, 1973; Collins \& Eriksen, 1967), only the increase from six- to eight-letter arrays can be explained by inhibitory interaction. The spacing between letters in two-, four-, and six-letter arrays was 2 , 1.41 , and $1 \mathrm{deg}$, respectively.

The second interpretation involves probabilistic switching from a cue to a no-cue strategy. If subjects failed to use the cue on a constant proportion of trials, and used a no-cue strategy by default, mean reaction time would represent a mixture of fast constant-latency cued responses and slower no-cue responses whose latency increased with array size. Note that this predicts greater variability with cues than without, since cued reaction time is a mixture of two distributions. Standard deviations in each condition were computed for each subject, and the means appear in Table 3. Wherever a cue reduced mean reaction time relative to the no-cue condition, cued standard deviations were smaller than in the corresponding no-cue condition. Thus, the data exclude the probabilistic switching interpretation.

Holmgren (1974) provides a third interpretation: Subjects first search for the cue, and then identify the letter associated with it without interference from the irrelevant letters. The increase in reaction time with array size reflects the time required to search for the cue; once the cue is found, the letter is identified with constant latency. While there is nothing in the present data to refute this interpretation, previous data may limit its applicability. Donderi and Zelnicker (1969) have shown that reaction time to detect a discrepant color in a multi-item array is constant over a wide range of array size. If such detection is equivalent to finding a cue, the cue-search interpretation cannot explain

Table 3

Mean Standard Deviations in Milliseconds for the Reaction Time Data in All Conditions of the Three Experiments

\begin{tabular}{|c|c|c|c|c|}
\hline \multirow[b]{2}{*}{ Condition } & \multicolumn{4}{|c|}{ Array Size } \\
\hline & 2 & 4 & 6 & 8 \\
\hline & \multicolumn{4}{|c|}{ Experiment 1} \\
\hline Control & 97 & 90 & 127 & 185 \\
\hline Red & 76 & 84 & 98 & 112 \\
\hline \multirow[t]{2}{*}{$45 \mathrm{deg}$} & 76 & 80 & 87 & 120 \\
\hline & \multicolumn{4}{|c|}{ Experiment 2} \\
\hline Control & 97 & 122 & 176 & 164 \\
\hline $15 \mathrm{deg}$ & 99 & 93 & 114 & 154 \\
\hline \multirow[t]{2}{*}{$30 \mathrm{deg}$} & 102 & 101 & 134 & 145 \\
\hline & \multicolumn{4}{|c|}{ Experiment 3} \\
\hline Control & 86 & 99 & 141 & 170 \\
\hline $15 \mathrm{deg}$ & 87 & 110 & 144 & 131 \\
\hline $30 \mathrm{deg}$ & 80 & 94 & 126 & 153 \\
\hline
\end{tabular}

the array-size effect found for red letters in Experiment 1.

A fourth interpretation is offered by Gardner (1973): Preparation for a cue involves increasing the weighting of information from a particular array position or set of feature detectors as it converges on a decision process. As long as the weights associated with irrelevant positions (or detectors) are nonzero, there will be more noise in the decision process the larger the array, and reaction time will increase with array size. In other words, using a cue does not eliminate processing in the other array positions, and this processing interferes with detecting the target. This appears to be consistent with the data.

In summary, the experiments have demonstrated that selective visual processing can occur efficiently without eye movements; the effect of irrelevant items was reduced (but not eliminated) when the target was cued. Moreover, greater savings were found when a particular cue could be used consistently. The efficiency of selection, then, appears to be variable and affected by array size, expectancy, and, possibly, cue type.

\section{REFERENCE NOTES}

1. Logan, G. D. On the nature of capacity limitations in visual search. $\mathrm{PhD}$ thesis, McGill University, 1975.

2. Logan, G. D., \& Withey, M. J. The efficiency of selection in the detection paradigm. Paper presented at the annual Meeting of the Eastern Psychological Association, New York, New York, April 1976.

\section{REFERENCES}

Averbach, E., \& Coriell, A. S. Short-term memory in vision. Bell System Technical Journal, 1961, 40, 309-328.

Collins, J. F. Independence of sensitivity on different foveal areas. Perception \& Psychophysics, 1973, 13, 212-216.

Collins, J. F., \& Eriksen, C. W. The perception of multiple simultaneously presented forms as a function of foveal spacing. Perception \& Psychophysics, 1967, 2, 369-373.

Dick, A. O. On the problem of selection in short-term visual (iconic) memory. Canadian Journal of Psychology, 1971, 25, 250-263.

Dick, A. O. Iconic memory and its relation to perceptual processing and other memory mechanisms. Perception \& Psychophysics, 1974, 16, 575-596.

Donderi, D. C., \& Zelnicker, D. Parallel processing in visual same-different decisions. Perception \& Psychophysics, 1969, 5, 197-200.

Estes, W. K. Interactions of signal and background variables in visual search. Perception \& Psychophysics, 1972, 12 , 278-286.

Gardner, G. T. Parallel perceptual processing and decisional strategies: A reinterpretation of the Shaw and LaBerge effect. Perception \& Psychophysics, 1973, 13, 517-518.

Holmgren, J. F. The effect of a visual indicator on rate of visual search: Evidence for processing control. Perception \& Psychophysics, 1974, 15, 544-550.

Neisser, U. Cognitive psychology. New York: AppletonCentury-Crofts, 1967.

Sperling, G. The information available in brief visual presentations. Psychological Monographs, 1960, 74, 1-29. 